\title{
Erratum to: Review of Wool Recycling and Reuse
}

Stephen Russell, Paul Swan, Mariell Trebowicz and Angus Ireland

\section{Erratum to:}

'Review of Wool Recycling and Reuse'

R. Fangueiro and S. Rana (eds.), Natural Fibres:

Advances in Science and Technology Towards Industrial

Applications, RILEM Bookseries 12,

DOI 10.1007/978-94-017-7515-1_33

The book was inadvertently published without the co-author names "Paul Swan and Mariell Trebowicz" of Chapter 33. The complete author names are given below:

Stephen Russell

Paul Swan

Mariell Trebowicz

Angus Ireland

The updated original online version for this chapter can be found at DOI 10.1007/978-94-017-7515-1_33

\footnotetext{
S. Russell $(\varangle) \cdot$ M. Trebowicz

Nonwovens Innovation and Research Institute, Leeds, UK

e-mail: s.j.russell@leeds.ac.uk

P. Swan · A. Ireland

Australian Wool Innovation Limited (AWI), Sydney, Australia

P. Swan · A. Ireland

International Wool Textile Organisation (IWTO), Brussels, Belgium

(C) RILEM 2016

R. Fangueiro and S. Rana (eds.), Natural Fibres: Advances in Science and Technology Towards Industrial Applications, RILEM Bookseries 12, DOI 10.1007/978-94-017-7515-1_36
}

E1 